\title{
Fundamentals of Transportation Problem
}

\section{B. Mallia, M. Das, C. Das}

\begin{abstract}
Transportation Problem is a linear programming problem. Like LPP, transportation problem has basic feasible solution (BFS) and then from it we obtain the optimal solution. Among these BFS the optimal solution is developed by constructing dual of the TP. By using complimentary slackness conditions the optimal solutions is obtained by the same iterative principle. The method is known as MODI (Modified Distribution) method.In this paper we have discussed all the aspect of transportation problem.
\end{abstract}

Keywords: Transportation Problem, Initial Basic Feasible Solution, Optimal Solution

\section{INTRODUCTION}

Transportation Problem is a special structure of Linear Programming Problem (LPP), that is frequently encountered in the Operation Research literature. The model was first presented by F.L. Hitchcock in 1941[28]. In 1950's simplexbased solution techniques were developed for the transportation problem exploiting its special structure. In the meantime, we come across varieties of transportation problems such as bottleneck problem, minimax and maximin problem, time minimization transportation problem, volume minimization transportation problem, etc. The bottleneck transportation problem was first discussed by Fulkerson, Glickberg, and Guss (1953) and subsequently by Guss in 1959[25]. Later on, varieties of new theoretical and methodological development were made by Hammer in 1969. Edmond and Fulkerson 1970, Garfinkle and Rao 1979 and 1976, Kaplan 1976 and Poisner and Wu 1981,[23] etc. Bottleneck models were mathematically formulated with a special type of objective function in which the maximal cost coefficient of any variable with strictly positive value is minimized concerning a given set of constraints.

As an example: suppose that the origin represents a military depot in which certain supplies, say ammunitions are stored and let the destination represent a combat zone at which there is specified demand for ammunition. To every depot combat zone pair, a coefficient $c_{i j}$ is assigned indicating the amount of time required to ship any number of units $\mathrm{i}^{\text {th }}$ origin to $\mathrm{j}^{\text {th }}$ destination. A military operation will start in all combat zone simultaneously at the earliest possible instance, it is necessary that the requested amount of ammunition must be available at all combat zones. In other words, the operation cannot start before the last shipment of goods arrives and the problem is to schedule the shipment so that the operation can start as soon as possible.

Manuscript received on May 18, 2021

Revised Manuscript received on May 24, 2021.

Manuscript publishedon June 30, 2021.

* Corresponding Author

Mrs. BhabaniMallia*, M.Phil., Statistics, Utkal University, Bhubaneswar, Odisha, India.

Dr. Manjula Das, Professor, Department, Centre for Applied Mathematics \& Computing, SOA deemed to be University, Bhubaneswar, Odisha, India.

Dr. C. Das, Professor, Department of Mathematics, NIIT, Rourkela, Odisha, India.

(c) The Authors. Published by Blue Eyes Intelligence Engineering and Sciences Publication (BEIESP). This is an open access article under the CC BY-NC-ND license (http://creativecommons.org/licenses/by-nc-nd/4.0/)

\subsection{Mathematical Formulation}

Throughout the thesis we will assume that the following structure is given: Let a company own "m" warehouses in which each of which there is a given amount of certain commodity in stock, and let there also be "n" consumer is with a given demand for this commodity. The "m" warehouses of the company are sources and "n" consumers are known as destinations. Moreover the unit transportation cost between each warehouse -consumer pair is known. The objective of the company is to transport units from the warehouses to the consumers, such that

i) no more units leave a warehouse than there are in stocks,

ii) the demands of the consumers are satisfied, and

iii) the total transportation cost is minimize

Formally the model can be described as follows: let $\mathrm{N}_{1}$ be a set of " $\mathrm{m}$ " location called origins so that there is a supply of $s_{i}$ at the $i^{\text {th }}$ origin, $i=1,2 \ldots . . m$ and let $N_{2}$ be a set of $n$ locations called destinations so that there is demand $d_{j}$ at the $j^{\text {th }}$ destination, $j=1,2 \ldots . . n$. In the above example, the origin corresponds to the warehouses whereas the retailers are represented by the destinations. we assume that the total demand equal to the total supply i.e $\sum_{i=1}^{m} s_{i}=\sum_{j=1}^{n} d_{j}$. If total supply exceeds total demands exactly one dummy destination is created to absorb the excess supply; its demand equals $\sum_{i=1}^{m} s_{i}-\sum_{j=1}^{n} d_{j}$. The case of excess demand is handed similarly using exactly one dummy origin.

Finally, it is assumed that exists exactly one connection between each origin-destination pair, that, detours are not allowed and that each of these connections has infinite capacity. The cost for shipping one quantity unit from the $\mathrm{i}^{\text {th }}$ origin to the $j^{\text {th }}$ destination is given by $c_{i j}$. All unit transportation costs from a dummy origin or to a dummy destination are assumed to be equal. Usually, we will set them equal to zero but sometimes, due to the specific nature of the problem considered, they will be assigned some other value. If the connection between $\mathrm{i}^{\text {th }}$ origin and $\mathrm{j}^{\text {th }}$ destination for some reason is forbidden, the corresponding cost is

assigned an extremely high value, i.e. we set $c_{i j}: M \gg 0$

. In these cases, the existence of feasible solutions is no longer guaranteed. Note that sometimes $\mathrm{C}_{\mathrm{ij}}$ denotes the distance per quantity unit; then the objective is to minimize the total distance of the shipments, assuming that each unit is transported separately. As in all linear programming problems, the objective function is linear. The above structure may be visualized in the following figure :

Published By: and Sciences Publication
Blue Eyes Intelligence Engineering

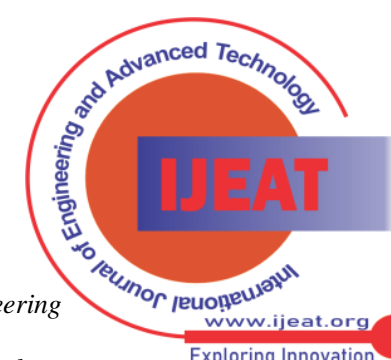




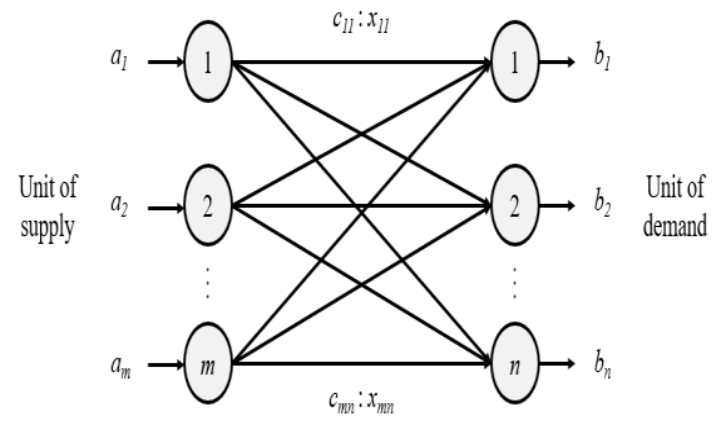

Fig-I
The above underlying structure is called bipartite graph; Defining variables $\mathrm{x}_{\mathrm{ij}}$ to denote the quantity shipped, from the $\mathrm{i}^{\text {th }}$ origin to the $\mathrm{j}^{\text {th }}$ destination, we can formulate the model

$$
\begin{aligned}
& \text { Primal problem } P: \min z=\sum_{i=1}^{m} \sum_{j=1}^{n} c_{i j} x_{i j} \\
& \begin{array}{c}
\text { s.t. } \sum_{j=1}^{n} x_{i j}=s_{i}, i=1,2 \ldots . . m \quad \text { (supply availability) } \\
\sum_{j=1}^{m} x_{i j}=d_{j}, j=1,2 \ldots . . n \quad \text { (demand requirements) } \\
x_{i j} \geq 0, i=1,2 \ldots . m \& j=1,2 \ldots . . n
\end{array}
\end{aligned}
$$

sometimes the supply constraints are given as constraints and/or the demand constraints are given as $\geqq$ relations; as long as $C_{i j} \geq 0 \forall i, j$ and $\sum_{i=1}^{m} s_{i}=\sum_{j=1}^{n} d_{j}$ the

$$
\begin{gathered}
P: \min z=\sum_{i=1}^{m} \sum_{j=1}^{n} c_{i j} X_{i j} \\
\text { s.t. } \sum_{j=1}^{n} x_{i j}<s_{i}, i=1,2 \ldots . m \\
=\sum_{j=1}^{m} a_{i j} x_{i j}>d_{j}, j=1,2 \ldots . . n \\
X_{i j} \geq 0, i=1,2 \ldots . . m \& j=1,2 \ldots . . n
\end{gathered}
$$

optimal solution remains unchanged. The above model has 'mn' variables $X_{i j}$ and $\mathrm{m}+\mathrm{n}$ constraints.

\subsection{The Generalised Transportation problem (GTP)}

In this subsection, we will Generalized Transportation problem(GTP). In mathematical term it can be written with same objective function as in (1)

\subsection{Properties and Solution Techniques}

Let us restate the primal problem with the understanding that a dummy has already been added if necessary: we reformulated problem (P)

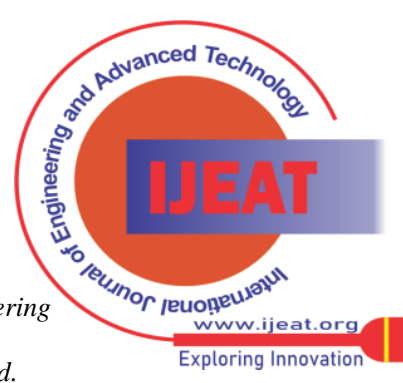




$$
\begin{aligned}
& P: \min z=\sum_{i=1}^{m} \sum_{j=1}^{n} c_{i j} x_{i j} \\
& \text { s.t. } \sum_{j=1}^{n} x_{i j}=s_{i}, i=1,2 \ldots . . m \\
& \sum_{j=1}^{m} x_{i j}=d_{j}, j=1,2 \ldots . . n \\
& x_{i j} \geq 0, \forall i, j
\end{aligned}
$$

After having transformed the above problem $\mathrm{P}$ into a maximization problem and multiplied all constraints by $(-1)$,

$$
\begin{aligned}
& P_{D} M a x w=\sum_{i \in J} s_{i} u_{i}+\sum_{i \in J} d_{i} v_{i} \\
& \text { subject to constraint } \\
& u_{i}+v_{i} \leq c_{i j} \\
& \text { where } u_{i}, v_{i} \in \mathbb{R} \\
& c_{i j}^{*} x_{i j}=0 \forall i, j \\
& \text { where } u_{i}, v_{i} \in \mathbb{R}
\end{aligned}
$$

Adding dual slack variables $C_{i j}^{*} \geq 0$ to the dual constraints, they can be written as

$$
u_{i}+v_{j}+c_{i j}^{*}=c_{i j} \forall i, j \text { or } c_{i j}^{*}=c_{i j}-u_{i}-v_{j} \forall i, j
$$

we assign dual variables $\mathrm{v}_{\mathrm{j}}$ to the next $\mathrm{n}$ primal constraints, and obtain the dual $\mathrm{P}_{\mathrm{D}}$ which can be written as:

Then the complementary slackness condition can be written as

$$
c_{i j}^{*} X_{i j}=0 \forall i, j
$$

The primal-dual relationship can be explained by the following situations: Suppose that a carrier Alpha has to ship supplies from origins to destinations where there is a pre-specified demand for the given product; Alpha wishes to minimize the total transportation costs. Now a competitor, say Beta, who feels that he can perform the task of shipping these units more efficiently than Alpha, approaches Alpha with the following offer: For each unit which Beta ships out of the ith origin, he will charge Alpha uidollars and for each unit which Beta delivers to the jthdestination, he charges Alpha vj dollars; the shipment will be done by Beta who uses Alpha's transportation facilities. To make this offer interesting for Alpha, Beta determines his prices ui and vj, so that Alpha will never have to pay more to Beta as if he would have spent transporting by himself (which is guaranteed by dual constraints). Moreover, Beta wants to maximize his profit, paid to him by Alpha, which is expressed in the dual objective function.

An application of the dual problem is described in the following situation: Let 'mn' machines Mij with capacities cij be given. Suppose that two types of chemicals are produced on these machines; the first type consists of chemicals A1, A2,........Am, so that Ajis produced on Mi1,

Consider, however , the k-th supply constraint $\sum_{j=1}^{n} x_{k j}=S_{k}$

and the remaining supply constraints $\sum_{j=1}^{n} x_{k j}=s_{i} \forall i \neq k$

$$
\sum_{j=1}^{n} x_{k j}=s_{i} \forall i \neq k
$$

Mi2,......Min and the second type consists of chemicals B1, $\mathrm{B} 2 \ldots . . . \mathrm{Bn}$, so that Bjis produced on $\mathrm{M} 1 \mathrm{j}, \mathrm{M} 2 \mathrm{j}$, ...Mmj. The production time is one time unit on each machine per quantity unit of either chemical; the unit selling price for $\mathrm{Ai}$ and $\mathrm{Bj}$ is ui and $\mathrm{vj}$, respectively. The company may decide to buy a certain amount of chemicals from the competition rather than to produce itself. The purchase price is identical to the company's selling price and the objective is to maximize the total profit of the company.

The solution of transportation problems is usually done with a two-phase method, very similar to the one described for the general simplex method. In phase 1 we find a primal basic feasible solution and in phase 2 the current primal solution is examined. If it is dual feasible and fulfills the complementary slackness condition, then it is optimal we stop; if this is not the case we perform one iteration and generate a new primal feasible basic solution which again becomes the input in phase 2 . Before procedures for phase 1 or 2 are described, we will focus on the properties of the basic solutions. Since the primal problem consists of $m+n$ constraints, each basic solution should consist of $m+n$ basic variables.

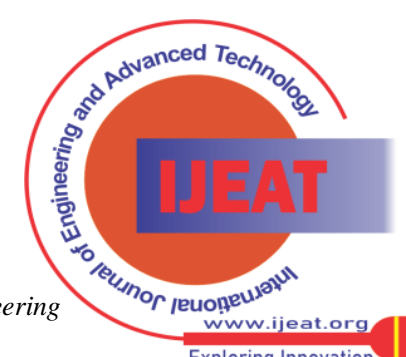

Exploring Innovation 
as well as the demand constraints

$$
\sum_{i=1}^{m} x_{k j}=d_{j} \forall j
$$

Then the supply-demand balance equation can be written

$$
s_{k}+\sum_{\substack{i=1 \\ i \neq k}}^{m} s_{i}=\sum_{j=1}^{n} d_{j} \text { or } s_{k}=\sum_{j=1}^{n} d_{j}-\sum_{\substack{i=1 \\ i \neq k}}^{m} s_{i}
$$

$$
\text { Summing of all constraints in (17) results in } \sum_{i=1}^{m} \sum_{j=1}^{n} x_{i j}=\sum_{j=1}^{n} d_{j}
$$

and summing up all constraints in (16) results in

$$
\sum_{\substack{i=1 \\ i \neq k}}^{m} \sum_{j=1}^{n} x_{i j}=\sum_{\substack{i=1 \\ i \neq k}}^{m} s_{i}
$$

Subtracting (17) from (16) yields

$$
\sum_{i=1}^{m} \sum_{j=1}^{n} x_{i j}-\sum_{\substack{i=1 \\ i \neq k}}^{m} \sum_{j=1}^{n} x_{i j}=\sum_{j=1}^{n} d_{j}-\sum_{\substack{i=1 \\ i \neq k}}^{m} s_{i} \text { or } \sum_{j=1}^{n} x_{k j}=\sum_{j=1}^{n} d_{j}-\sum_{\substack{i=1 \\ i \neq k}}^{m} s_{i}
$$

Using (6) we obtain $\sum_{j=1}^{n} x_{k j}=S_{k}$ which is identical to (12) above.

In other words, the k-th supply constraint can be derived from all other constraints. In general, any of the primal constraints can be expressed as a linear combination of the others. By the same token, no basis of transportation problem can include more than $(m+n-1)$ basic variables, because if it did, it would be linearly dependant which is impossible by the definition of a basis.

In the following, we will continue a technique that leads to a basic feasible solution. i.e. which perform the task of phase 1. Although for the time being it will be assumed that all problems are non-degenerate (primal as well as dual), we will describe later in the chapter how to deal with any kind of degeneracy. Set up an[m $\times \mathrm{n}]$ dimensional transportation table where the i-th row corresponds to the ith origin and the $\mathrm{j}$-th column represents the $\mathrm{j}$-th destination so that the element $(i, j)$ denotes the value of xij. Suppose now that any element is selected, say the entry in the i-th row and the s-th column, and set xrs:=min $\{\mathrm{sr}$, ,ds $\}$. Assume that $\mathrm{xrs}=\mathrm{sr}<\mathrm{ds}$, then the supplies and demands are redefined as

$$
s_{i}:\left\{\begin{array}{l}
0 \text { if } i=r \\
s_{i} \text { otherwise }
\end{array} \text { and } d_{j}:=\left\{\begin{array}{l}
d_{j}-s_{r}, \text { if } j=s \\
d_{j} \text { otherwise }
\end{array}\right.\right.
$$

In other words, since $s_{\mathrm{r}}$ units are shipped out of the r-th origin, no more units are left there and the current supply is zero; since these $s_{\mathrm{r}}$ units are shipped to the s-th destination the demand in this destination is satisfied in parts, the remaining demand is $d_{s}-s_{r}$. All other supplies and demands are unaffected by this shipment since there is no more supply in the r-th origin, so that all elements $x_{\mathrm{rj}}, j \neq s$ can be set equal to zero. We proceed similarly if $\mathrm{x}_{\mathrm{rs}}=\mathrm{d}_{\mathrm{s}}$; in this case, set $X_{i s}:=0 \forall i \neq r$.
After going through this procedure once, we have assigned values to all elements in either one row or one column, i.e. the $[m \times n]-$ the dimensional problem has been reduced to a $[(m-1) \times n]$ or to a $[m \times(n-1)]$ - dimensional problem. This process can be repeated until values have been assigned to all 'mn' variables. This task requires exactly $(m+n-1)$ steps such as the above (note that in the last step the remaining supply equals the remaining demand since

$$
\sum_{i=1}^{m} s_{i}=\sum_{j=1}^{n} d_{j}
$$

.) Moreover, since in each of these $(m+n-1)$ steps exactly one of the assigned values is positive: the corresponding variable is basic in the current solution, i.e. the number of resulting basic variables complies with their required number. The open question at this point concerning the above procedure is how to select a specific element among all those to which values have not yet been assigned. In the above description, we choose any element, although specific rules can be designed to find an initial solution that is as good, i.e. close to the optimal solution, as possible.

Before describing any of the many possible rules, we should note that

(a) none of the rules assures that the initial solution is optimal.

(b) none of the rules, no matter how sophisticated, has been proved superior to any other rule, no matter how elementary. In other words, it is always possible to construct examples, for which simple rules find better initial solutions than the rules which are generally considered good.

Published By: Blue Eyes Intelligence Engineering 
On average, however, extensive test series indicated that certain rules are much more effective than others. Some of these rules will be presented at the end of this chapter in algorithmic form. A more complete survey can be found in Eiselt and von Frajer (1977).

At this stage, we enter phase 2 and determine if the current primal feasible solution is also dual feasible, i.e. optimal. The procedure to be described in the following is called the MODI or Modified Distribution method. Recall that the dual constraints are

$$
\begin{aligned}
c_{i j}^{*} & =c_{i j}-u_{i}-v_{j} \text { where } c_{i j}^{*} \text { are the dual slacks, } \\
u_{i}, v_{j} & \in \mathbb{R} \forall i, j \text { and } c_{i j}^{*} \geq 0 \forall i, j
\end{aligned}
$$

and that the complementary slackness condition can be written as $C_{i j}^{*} X_{i j}=0 \forall i, j$. To fulfil the complementary slackness condition, we set $c_{i j}^{*}=0 \forall i, j$ such that xij $>0$. Note that the values of all primal and dual variables can be found in a corresponding primal simplex tableau in the positions indicated below.

\begin{tabular}{|c|c|c|}
\hline $\mathrm{x}_{\mathrm{i}}$ & $\mathrm{A}_{1}, \mathrm{~A}_{2}, \ldots \ldots \ldots \mathrm{A}_{\mathrm{m}+\mathrm{n}}$ & $\mathrm{I}$ \\
\hline & & $\begin{array}{l}\text { Values of } x_{i j} \\
i=1,2 \ldots \ldots . m \\
j=1,2 \ldots \ldots . n\end{array}$ \\
\hline $\begin{array}{l}\text { Values of } c_{i j}^{*} \\
\mathrm{i}=1,2 \ldots \ldots \mathrm{m} \\
\mathrm{j}=1,2 \ldots \ldots . \mathrm{n}\end{array}$ & $\begin{array}{l}\text { Values of } \\
\mathrm{i}=1,2 \ldots \ldots . \mathrm{m} \\
\text { and } \\
\mathrm{j}=1,2 \ldots \ldots . \mathrm{n}\end{array}$ & \\
\hline
\end{tabular}

Table-I

The above complementary slackness condition assures that under each $x i j>0$, which accordingly has to be a basic variable, a zero is found $c_{i j}^{*}=0$ in the objective function row. Since (any) one of the primal constraints is redundant, (any) one of the dual variables ui or vj can assume an arbitrary value; for reasons of simplicity set v1: $=0$. Since v1 belongs to the first destination and since $d 1>0$, there must be at least one index $\mathrm{i}$, such that xi1 $>0$ and thus $C_{i 1}^{*}=0$. Using this information in (1), we obtain ui $+v 1=$ cij, where $u 1$ is the only unknown in this equation. We solve for ui and then proceed in exactly the same way, taking one $c_{k l}^{*}=0$ at a time, where either ukor vl has already been calculated and solve relation (1) for the unknown dual variable. After $(m+n-1)$ calculations of this type, all dual variables ui and vj have been determined. After this task has been accomplished, relations (1) are used again, i.e. for all nonbasic variables xij for which the corresponding $C_{i j}^{*}$ values are still unknown, we use $C_{i j}^{*}=C_{i j}-u_{i}-v_{j}$ where $C_{i j}^{*}$ is the only unknown.

The above relation is used $(\mathrm{mn}-\mathrm{m}-\mathrm{n}+1)$ times after which all ${ }^{C_{i j}^{*}}$ values are determined. Therefore all-right hand side values and all objective function coefficients in the simplex tableau corresponding to the current solution have been determined. This enables us to evaluate the current solution concerning optimality. Recall that the solution is primal feasible and setting $c_{i j}^{*}=0$ for all basic variables xij assures that the complementary slackness condition is fulfilled. Hence if $c_{i j}^{*} \geq 0 \forall i, j$. we can conclude that the current solution is also dual feasible and thus optimal, in which case we would stop here. If however, there exists at least one $C_{i j}^{*}<0$, optimality has not yet been established and at least one more iteration is necessary, i.e. the current basis has to be changed. In a simplex tableau such as the one displayed previously, we would select any negative $C_{i j}^{*}$ and introduce the corresponding variable xij into the basis. Note that in general more than one negative $c_{i j}^{*}<0$

element is given so that we have the choice of which variable enter the basis. Using an equivalent of the steepest unit ascent method, we would select the variable with the smallest $C_{i j}^{*}<0$ value. Note, however, that all variables with negative $C_{i j}^{*}$ values are eligible for introduction into the basis.

Suppose that the current primal solution is displayed in a transportation table $\mathrm{T}$, with ' $\mathrm{m}$ ' rows and ' $\mathrm{n}$ ' columns; so that the value in the i-th row and the $j$-th column is the current value of the variable xij. Introducing a variable xij into the basis in a non-degenerate simplex tableau means increasing its value from zero to some positive number say $\in>0$. Suppose that xij will be introduced into the basis and that we indicate this by labelling the corresponding element in the $\mathrm{T}$ table by $"+\in "$ or $"+$ " for short. If, however, we increase the value of xij by some positive number without making any other adjustments, we use more of the supply in the i-th origin than is available and at the same time more than required is shipped to the $\mathrm{j}$-th destination. Considering the origin only, we have to subtract the same amount $\in$ from some other element in the

i-th row, say $X_{i \ell}$, which will receive the label "- $\in$ " or "". Now the amount, shipped out of the i-th origin equals si but the $\ell^{\text {th }}$ destination receives less than its demand, whereas the $\mathrm{j}$-th destination receives more than its demand.

Published By:

Blue Eyes Intelligence Engineering and Sciences Publication 
Hence an element it the $\ell^{\text {th }}$ column will receive a " +" label, say $X_{k \ell}$, then an additional "-" label is required in the k-th row and so on. It should be pointed out here that except for the first "+" label, which was assigned to a nonbasic entry, all other labels, "+" or " _ " can only be assigned to basic variables. Labels assigned to additional non-basic variables would indicate the simultaneous introduction of multiple variables into the basis (block pivoting). Note that the above labelling procedure stops as soon as each row and column includes the same number of "+" and " _" labels or, equivalently, that an alternating cycle of "+" and " - " labels is formed. The figures below display three possible $(+,-)$ cycles:

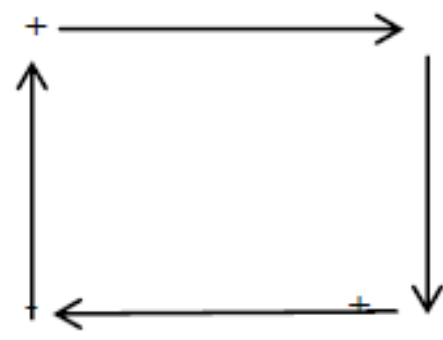

Fig -II(a)

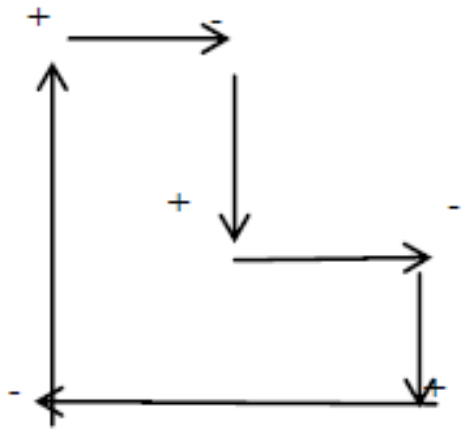

Fig -II(b)

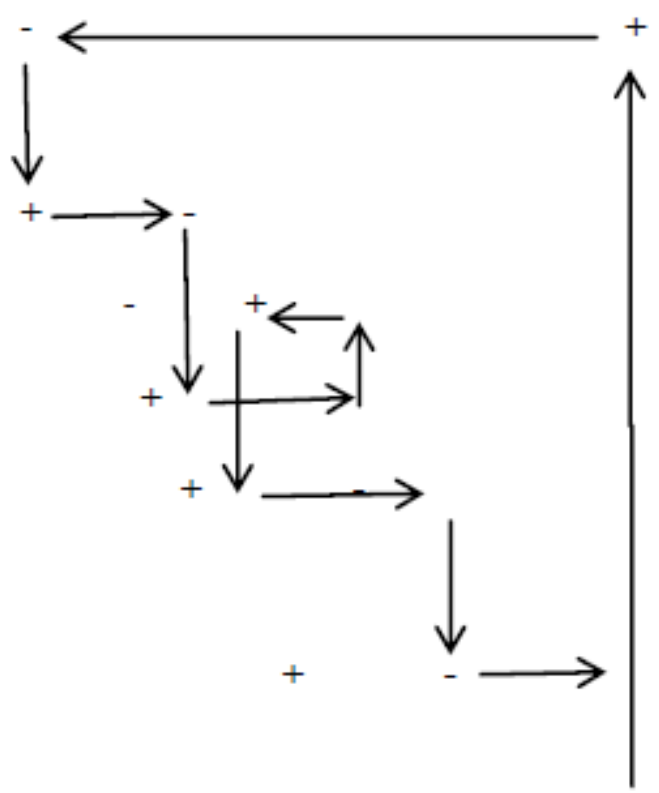

Fig -II(c)
Before the question of existence of $(+,-)$ cycles is addressed, we will discuss the change in the solution which results from the cycle determined above. Let $M$ be set consisting of all elements, which have received a "_" label above. Determine $\in:=\min \left\{x_{i j} \mid(i, j) \in M\right\}$ i.e. $\in$ is the minimum value among all those xij, that will be reduced in the next solution. We now add $\in$ to all elements with a "+" label, subtract $\in$ from all elements in $M$ and leave the remaining elements unchanged. It is easy to show that the new solution, generated by this procedure, is primal feasible: since in all rows and columns the same amounts are added as well as subtracted, the supply and demand constraints remain fulfilled. Furthermore the rule for the determination of $\in$ ensures that the non-negativity constraints for all variables xij are still fulfilled, and hence the new transportation plan is again primal feasible. Moreover, it has already been stated that the element, where the $(+,-)$ cycle started, is introduced in the basis; one variable is reduced to zero, namely the one which determined the value of $\in$; this is the variable that leaves the basis. As a result, the new solution is not only primal feasible but it is also a basic solution. Note also the effects of changing the values on the $(+,-)$ cycle by a value $\partial \neq \in$ .If $\partial>\in$, then at least one $x i j<0$ ( the one which determined $\epsilon$ ); If $\partial<\epsilon$, then no variable is reduced to zero which means that due to the fact that one variable enters the basis, too many variables have values greater than zero, i.e. the resulting solution is no longer a basic solution. If more than one variable determines $\in$, we face a case of primal degeneracy, and we will explain below how these cases can be handled.

Now a new solution, i.e. a new transportation plan, has been determined and we start again with phase 2, examining if the current solution is optimal or not. This procedure is repeated until the stop criterion is fulfilled, i.e. until $C_{i j}^{*} \geq 0 \forall i, j$

Before discussing degeneracy, we outline certain properties of basic solutions in transportation problems. We will say that a given set of elements (variables) form a cycle. If we could assign "+" and "_" labels to these elements, so that a $(+,-)$ cycle, including all elements in the above set, will result. Then we can state the following

\section{Lemma I. The variables in any basis do not form a cycle.}

Proof: Suppose they do. Then there exists a sequence of basic variables xj0 j1, xj1 j2, xj2 j3 , .....,xjr-1jr, xjr j0 . Since each row and column includes an even number of variables in the cycle, the total number of variables in the cycle is even, and thus ' $r$ ' is odd. Let ${ }^{{ }^{j} j \ell j k}$ the column of coefficients associated with the variable ${ }^{X_{j \ell j k}}$, so that

$$
a_{. j \ell j k}[0, \ldots \ldots .0 .1,0, \ldots \ldots, \ldots . ., 0,1,0, \ldots \ldots ., 0] \mathrm{T} \text { is the vector }
$$
with elements equal to one in the $j \ell-t h$ and jk-th position and zeros otherwise, i.e.

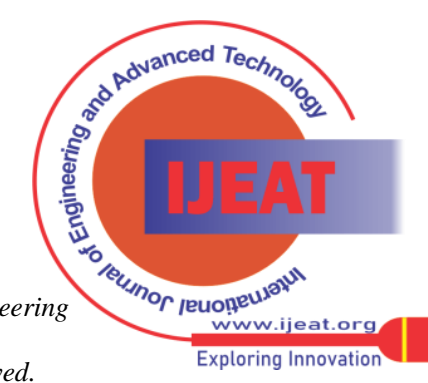


$a_{. j \ell j k}=e_{j \ell}+e_{j k}$, where ej is the $\mathrm{j}$-th unit vector. By assumption we can form a (+, -) cycle with the above variables, such that

$$
\begin{array}{r}
a_{\cdot j_{0} j_{1}}-a_{\cdot j_{1} j_{2}}+a_{\cdot j_{2} j_{3}}-a_{\cdot j_{3} j_{4}}+\ldots \ldots . .+a_{\cdot j_{r-1} j_{r}}-a_{\cdot j_{r} j_{0}}= \\
=\left[\sum_{\mu=0}^{\frac{r-1}{2}} a_{\cdot j_{2 \mu} j_{2 \mu+1}}\right]-\left[\sum_{\mu=0}^{\frac{r-3}{2}} a_{\cdot j_{2 \mu+1} j_{2 \mu+2}}+a_{\cdot j_{r} j_{0}}\right]=
\end{array}
$$$$
\left[\begin{array}{l}
0 \\
\cdot \\
\cdot \\
\cdot \\
1 \rightarrow j_{0} \\
\cdot \\
\cdot \\
1 \rightarrow j_{r} \\
0 \\
\cdot \\
\cdot \\
\cdot \\
0
\end{array}\right]-\left[\begin{array}{l}
0 \\
\cdot \\
\cdot \\
\cdot \\
1 \rightarrow j_{0} \\
\cdot \\
1 \rightarrow j_{r} \\
0 \\
\cdot \\
\cdot \\
\cdot \\
0
\end{array}\right]=\left[\begin{array}{l}
0 \\
\cdot \\
\cdot \\
\cdot \\
0 \rightarrow j_{0} \\
\cdot \\
\cdot \\
0 \rightarrow j_{r} \\
0 \\
\cdot \\
\cdot \\
\cdot \\
0
\end{array}\right]
$$

The columns of the basis are linearly dependent, which is a contradiction. This proves the lemma.

In graph-theoretical terms, every basic solution of a transportation problem forms a tree in a bipartite graph. The addition of one more variable is in a tree (introduction of a variable into the basis) results in the creation of exactly one cycle, which is the $(+,-)$ cycle used in phase 2 . Since this concept is closely related to the case of primal degeneracy, we will use such a degenerate example to explain the above. Let a transportation problem with three origins and three destinations be given, for which the supplies are 50,10 , and 40 , respectively and the demands are 20,40, and 40 respectively. We will use a technique called the Northwest Corner Rule (formally described later ) to set up the initial transportation plan, the following five tables may explain the dynamics of the procedure, and the * indicates the element selected in the respective northwest corner. Note that the supplies and the demands are adjusted as soon as a value has been assigned to the selected element.

Table-II

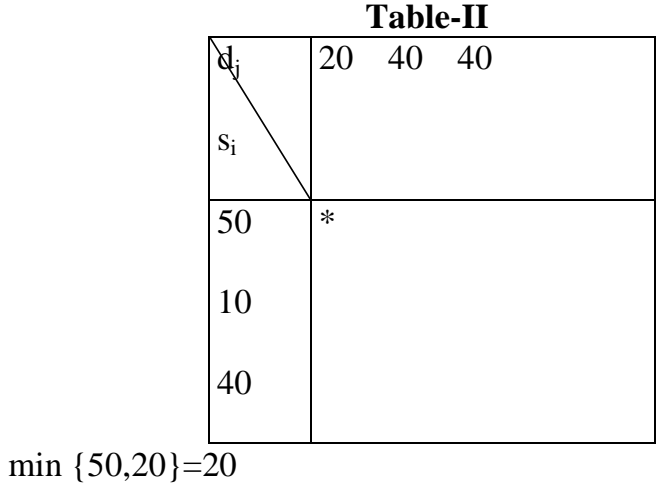

Table-III

\begin{tabular}{|l|lll|}
\hline $\mathrm{d}_{\mathrm{j}}$ & 0 & 10 & 40 \\
$\mathrm{~s}_{\mathrm{i}}$ & & & \\
\hline 0 & 20 & 30 & 0 \\
10 & 0 & 10 & 0 \\
40 & 0 & 0 & 40 \\
\hline
\end{tabular}

$\min \{30,40\}=30$

Table-IV

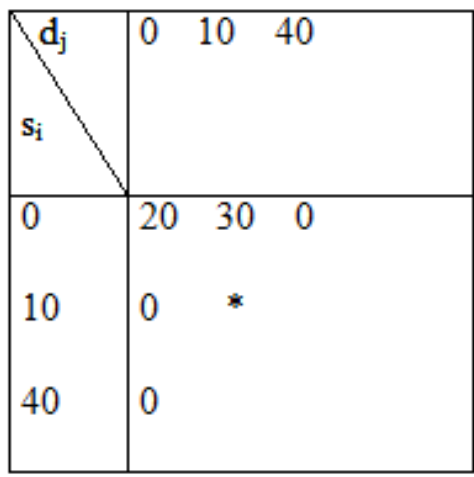

$\min \{10,10\}=10$

Table-V

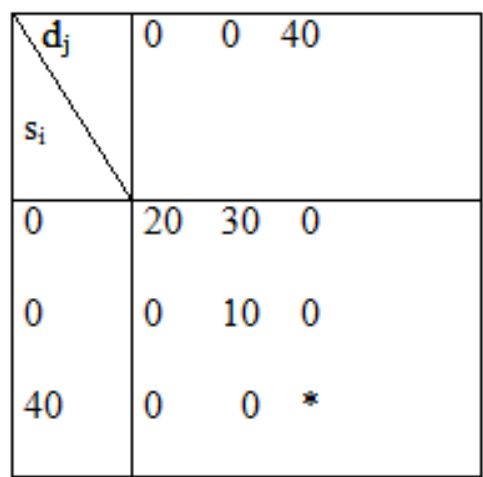

$\min \{40,40\}=40$

Table-VI

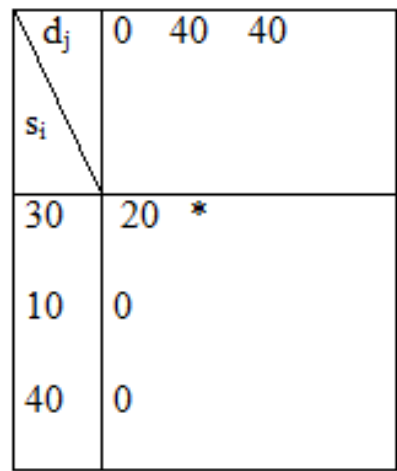

Published By:

Blue Eyes Intelligence Engineering 
In the third of the above tables, the (reduced ) supply equals the (reduced) demand for the selected element. Hence after assigning the value to the corresponding variable, both row and column have to be filled up with zeros since neither supply nor demand is left. ( Note that this phenomenon always occurs when the last assignment is made - table 4 above - since total supply equals total demand). A result is that not all basic variables in the initial transportation plan can be identified. In the above example $\mathrm{m}=\mathrm{n}=3$, and although $(m+n-1)=5$ basic variables are needed, only four, namely $\mathrm{x} 11=20, \mathrm{x} 12=30, \mathrm{x} 22=10, \mathrm{x} 33=40$ can be identified. It is now necessary to locate the remaining basic variable. This will become clear when we try to set up the matrix of dual slack $C^{*}=\left(C_{i j}^{*}\right)$ called opportunity cost matrix or shadow price matrix (due to reasons which will be explained later ). Setting $c_{i j}^{*}=0 \forall x_{i j}>0$ as well $v_{1}=0$ we obtain

Table-VII

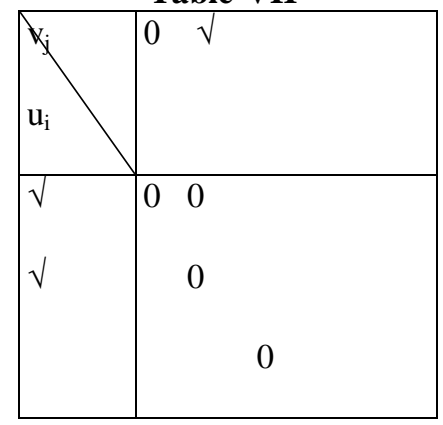

Using $\mathrm{c}^{*} 11=0$ and $\mathrm{v} 1=0$, we determine $\mathrm{u} 1$, using $\mathrm{u} 1$ and $c_{12}^{*}=0$ we determine $\mathrm{v} 2$ and using $c_{22}^{*}=0$ we determine u2. At this point, it is no longer possible to calculate any additional dual variable u1 or vj. The most general rule to overcome this problem is to assign a "basic zero", denoted by bv0, to any element, which helps to calculate an additional dual variable uior vj. In the above example, a basic zero in position $(1,3)$ would make it possible to calculate v3 (using $\mathrm{u} 1$ and $\mathrm{c} * 33=0$ ), in position $(2,3)$ we could calculate v3 ( using u2 and $c^{*} 23=0$ ), in position $(3,2)$ we could calculate u3 (using v2 and c*32=0) and in position $(3,1)$ calculate $\mathrm{u} 3$, using $\mathrm{v} 1$ and $\mathrm{c} * 31=0$. Any of the above positions for an additional basic zero is acceptable. We can, however, not assign a basic zero $(2,1)$, as this would not help to calculate any additional variables $\mathrm{u} 1$ or vj since $\mathrm{u} 2$ as well as v1 have already been determined. The initial solution for our small example can also be displayed as follows:

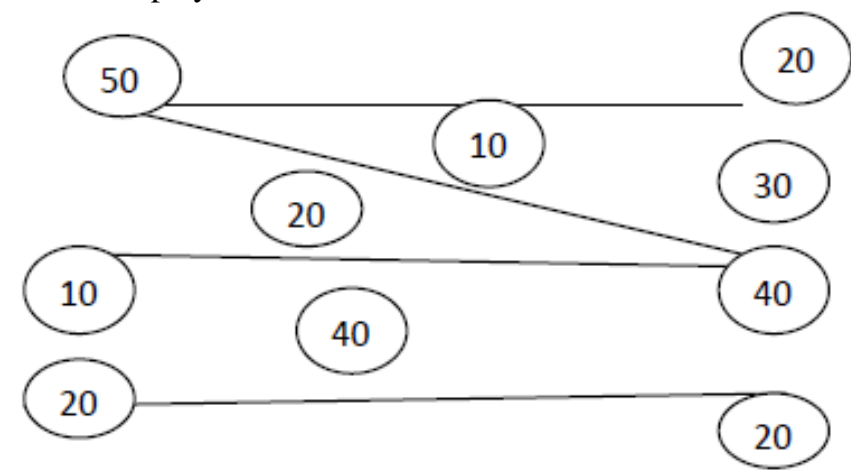

Fig -III
It can be seen in Fig-III that an additional basic variable x21 would introduce an additional connection between origin 2 and destination 1 ( with the shipped amount of zero) and would thus create a cycle in the above graph, which is forbidden in basis. Every other additional connection does not create a cycle and is hence possible.

Primal degeneracy can, of course, also occur during phase 2. Suppose that for some solution a $(+,-)$ cycle has been found and let the value of $\in$ be determined by two or more elements, i.e. various elements with "_" labels have the same minimum value. Since only one element can leave the basis in one iteration, we select any of these elements (the selection is arbitrary, additional criteria e.g. the one with the highest original cost coefficient cij or any other rule can be used) to leave the basis. Any other element which could have been selected for leaving the basis will have a zero value in the next solution, and we will indicate the fact that it is still in the basis by the superscript " by" ( hence, in the next $C^{*}$ matrix, there $\mathrm{c}^{*} \mathrm{ij}$ coefficients will be set equal to zero right away).

Finally, the case of dual degeneracy will be described. Suppose that for any solution, the dual variables uiand vjhave already been determined and in the process of calculating the $\mathrm{c}^{*} \mathrm{ij}$ coefficients for the non-basic variables using relation (1), it turns out that at least one of the $c^{*} \mathrm{ij}$ values equals zero. This is the case of dual degeneracy. From a procedural point of view, we may ignore it as long as it occurs in an intermediate, i.e. non-optimal, solution. If dual degeneracy occurs, however, is an optimal solution, it indicates - according to simplex theory the existence of alternative optimal solutions. They can be generated by starting a (+,-) cycle with a non-basic variable for which $\mathrm{c}^{*} \mathrm{ij}$ $=0$ and then using the regular procedure. The above discussion about degeneracy is summarized in the following :

Table-VIII

\begin{tabular}{|c|c|c|}
\hline \\
\hline Case & Occurrence & Treatment \\
\hline $\begin{array}{l}\text { Primal } \\
\text { degeneracy, } \\
\text { Phase } 1\end{array}$ & $\begin{array}{l}\mathrm{S}_{\mathrm{i}}=\mathrm{d}_{\mathrm{j}} \text { for the } \\
\text { selected } \\
\text { element } \mathrm{x}_{\mathrm{ij}}\end{array}$ & $\begin{array}{l}\text { Introduce a basic } \\
\text { variable } \\
\mathrm{x}_{\mathrm{ij}}=0 \text { wherever it } \\
\text { helps to calculate } \\
\text { one more dual } \\
\text { variable } \mathrm{u}_{\mathrm{i}} \text { or } \mathrm{v}_{\mathrm{j}}\end{array}$ \\
\hline $\begin{array}{l}\text { Primal } \\
\text { degeneracy } \\
\text { Phase } 2\end{array}$ & $\begin{array}{l}\epsilon \text { is } \\
\text { determined } \\
\text { by more } \\
\text { than one } \\
\text { element }\end{array}$ & $\begin{array}{l}\text { Select as leaving } \\
\text { variables one } \\
\text { Which determined } \\
\epsilon \text {, indicate that } \\
\text { other elements } \\
\text { remain on the basis. }\end{array}$ \\
\hline
\end{tabular}

Published By: Blue Eyes Intelligence Engineering 


\begin{tabular}{|l|l|l|}
\hline $\begin{array}{l}\text { Dual } \\
\text { degeneracy }\end{array}$ & $C_{i j}^{*}=0$ \\
& $\begin{array}{l}\text { for a non- } \\
\text { basic } \\
\text { variable } \mathrm{x}_{\mathrm{ij}}\end{array}$ & $\begin{array}{l}\text { In the final tableau, } \\
\text { generate } \\
\text { alternative optimal } \\
\text { solutions by } \\
\text { starting a (+,-) on } \\
\text { any of the } \\
\text { non-basic variables } \\
\text { with } C_{i j}^{*}=0\end{array}$ \\
\hline
\end{tabular}

One final note before the above algorithm is described formally is concerned with maximization rather than minimization problems. There are various ways to handle maximization problems, three of which are :

(1) Transform the maximization problem into a minimization problem by multiplying all coefficients cij by $(-1)$; the algorithm remains unchanged.

(2) Find the highest unit of profit, says crs, (i.e $c_{r s}=\max _{i, j}\left\{c_{i j}\right\}$ ) and determine pseudo costs $\hat{c}_{i j}:=c_{r s}-c_{i j} \forall i, j$. Then $\hat{C}=\left(\hat{c}_{i j}\right)$ is used together with the regular minimization procedure.

(3) Change the algorithm, so that a $(+,-)$ cycle starts with some $\mathrm{xij}$, for which $\mathrm{c} * \mathrm{ij}>0$ as soon as $C_{i j}^{*} \leqq 0$ (rather than $\geqq 0 \forall i, j$ )

In the following, we will describe a solution technique for the minimization transportation problem, which includes three alternative procedures for phase 1 and MODI procedure for phase 2 . To simplify the notion in phase 1 , let $\mathrm{Q}$ be the set of elements (i,j), to which no value has been assigned yet. Initially, Q includes all 'mn' elements (i,j).

\section{METHODS}

\section{Northwest Corner Rule (NWC)}

Start with NWC of the transportation table A allocates the minimum of row one or column one. If row 1 is satisfied, then move vertically to the next cell of column 1 and allocate the remaining quantity cell $(2,1)$, if the column is satisfied. Then move horizontally to the next cell and allocate the minimum of row 2 and column 2 . In cell $(2,2)$ we continue the movement vertically and horizontally when we reach the last corner of the T.P..The total movement no doubt generate $m+n-1$ cells. Then we find out the initial BFS and corresponding cost by multiplying the corresponding cost of the cell.

\section{Algorithm}

Step 1: Select $(r, s)$ such that $r+s=\min \{i+j \mid(i, j)$ $\in \mathrm{B}\}$ and set $\mathrm{xrs}=\min \{\mathrm{sr}, \mathrm{ds}\}$

Step 2: Is xrs = sr?

$$
\begin{aligned}
& \text { If yes: Go to step } 3 . \\
& \text { If no: Go to step } 4 .
\end{aligned}
$$

Step 3: Set sr $=$ sr- $x r s=0$, ds : $=$ ds - xrs, xrj :=0 $\forall(\mathrm{r}, \mathrm{j}) \in \mathrm{B}$ an redefine and stop the procedure,

$\mathrm{B}:=\mathrm{B} \backslash \cup\{(\mathrm{r}, \mathrm{j}) \mid(\mathrm{r}, \mathrm{j}) \in \mathrm{B}\}$. Go to step 5

Step 4: Set ds : $=$ ds $-x r s=0$, sr $:=$ sr $-x r s$, xis $:=0$ $\forall(\mathrm{i}, \mathrm{s}) \in \mathrm{B}$ and redefine

Step 5: Is B $=\varnothing \quad$ ?

$$
\mathrm{B}:=\mathrm{B} \backslash\{(\mathrm{i}, \mathrm{s}) \mid(\mathrm{i}, \mathrm{s}) \in \mathrm{B}\}
$$

If yes: Stop, a feasible transportation plan has been found.

If no: Go to step 1.

Alternatively, we can use the

\section{Least Cost Method (LCM)}

$$
\begin{gathered}
\text { Step } \quad 1: \quad \text { Select } \quad(\mathrm{r}, \mathrm{s}), \quad \text { such that } \\
c_{r s}=\min \left\{c_{i j} \mid(i, j) \in Q\right\}
\end{gathered} \text { and set } x_{r s}=\min \left\{s_{r}, d_{s}\right\} \text {. }
$$

Steps 2 through 5 are identical to the ones in the Northwest Corner Rule. If in step 5 the answer is "no", one simply returns to step 1 rather than the one in NWC.

A third possibility is

\section{Vogel's Approximation Method (VAM)}

Step 1: for each row (column ), containing at least two unassigned elements, calculate penalties pi (qi), so that pi (qi) is the absolute value of the difference between the value of the minimal and the second minimal original cost coefficient, belonging to unassigned elements in the i-th row (j-th column ). Determine the row or column with the maximal penalty. If this is row $\mathrm{r}$, determine $(\mathrm{r}, \mathrm{s})$, so that crs $=\min \{\operatorname{crj} \mid(r, j) \in \mathrm{B}\}$; if this column $\mathrm{s}$, determine $(\mathrm{r}, \mathrm{s})$, so that crs $=\min \{\operatorname{cis} \mid(\mathrm{i}, \mathrm{s}) \in \mathrm{B}\}$. Set $x_{r s}=\min \left\{s_{r}, d_{s}\right\}$

From this point on we can again use Steps 2 through 5 described above under the Northwest Corner Rule. It can easily be seen that the only difference between these procedures is the selection of the element $(\mathrm{r}, \mathrm{s})$. Whereas we pay no attention whatsoever to the cost if the Northwest Corner Rule is used (in fact, the NWC rule will find identical solutions for transportation problems with the same supplies and demands, no matter what the costs are ), the cost structure is considered in different ways in other two methods. Whereas it is considered worthwhile to assigned as many units as possible to the element with the lowest unit cost in the LCM, we consider the relative magnitude of the unit costs in VAM. The penalties can be seen as an approximation of the additional costs which are incurred per quantity unit if the lowest cost element in a row or column is not selected, in which case the next best choice would be the element with the second-lowest-cost). Accordingly, the row or column with the highest penalty is one in which it seems most important to assign units to the lowest cost element because otherwise, the (high) penalty comes into effect. For the LCM and VAM methods, it is important what costs are assigned to the entries in the dummy row or column. If these costs are consumed to be zero, then the corresponding entries are undoubtedly attractive for minimization purposes; with LCM for example we will start assigning values to one of the dummy connections. At first sight, it might appear that it would not make any real difference what xijvalues are assigned to dummy connections. The situation is quite the opposite.

Published By:

Blue Eyes Intelligence Engineering

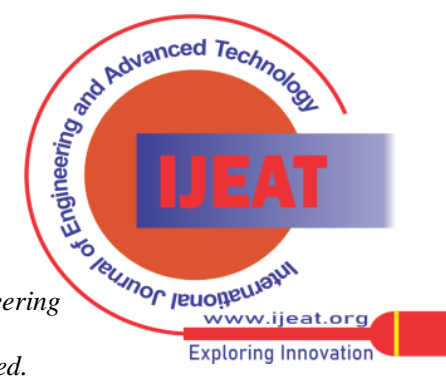


One can easily show that in many cases it is beneficial either to assign high costs to dummy connections or, equivalently, to disregard their cost coefficients for the selection of xrs. After any basic feasible solution has been found ( e.g. with one of the above methods ),

** We solve one example of transportation problem by NWC and VAM and see which one is better

North West Corner rule:

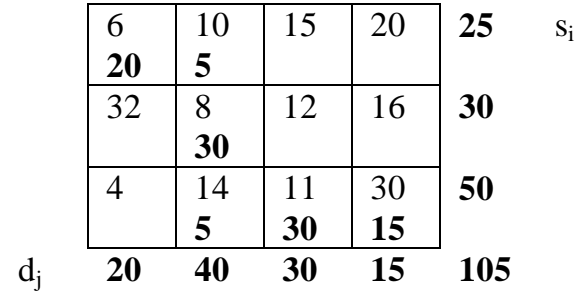

$\mathrm{Z}=(6 * 20)+(10 * 5)+(8 * 30)+(14 * 5)+(11 * 30)+(30 * 15)=1260$

Vogel's Approximation Method (VAM):

\begin{tabular}{|c|c|c|c|c|}
\hline 6 & $\begin{array}{l}10 \\
25\end{array}$ & 15 & 20 & 25 \\
\hline 32 & $\begin{array}{l}8 \\
15\end{array}$ & 12 & $\begin{array}{l}16 \\
15\end{array}$ & 30 \\
\hline $\begin{array}{l}4 \\
20\end{array}$ & $\begin{array}{l}14 \\
0\end{array}$ & $\begin{array}{l}11 \\
30\end{array}$ & 30 & 50 \\
\hline 20 & 40 & 30 & 15 & 105 \\
\hline
\end{tabular}

$\mathrm{Z}=(10 * 25)+(8 * 15)+(16 * 15)+(4 * 20)+(14 * 0)+(11 * 30)=1020$

It is found that VAM is better than NWC

we proceed with the MODI method, which can be summarized as follows:

\section{Modified Distribution Method (MODI)}

\section{Step1:Set}

$c_{i j}^{*}=0 \forall i, j$, for which $x_{i j}$ is a basic var iable.

Step 2 :Set $v 1=0$ and calculate ui , i=1,2,....m and vj, $\mathrm{j}=1,2, \ldots$, so that

$$
u_{i}+v_{j}=c_{i j} \forall(i, j) \mid c_{i j}^{*}=0
$$

Step 3: Determine $C_{i j}^{*}$ for all non-basic variables xij , so that $C_{i j}^{*}=C_{i j}-u_{i}-v_{j}$.

Step 4: Does there exist at least one $c_{i j}^{*}<0$ ? If yes: Go to step 5

If no: Stop, the current transportation plan is optimal.

Step5: Select any element $(\mathrm{r}, \mathrm{s})$ for which $c_{r s}^{*}<0$ e.g. $c_{r s}^{*}=\min \left\{c_{i j}^{*} \mid c_{i j}^{*}<0\right\}$

. Label xrs with "+" and determine a $(+,-)$ cycle in the current transportation plan with labels on basic entries only (except $(r, s))$.

Step 6: Let $\mathrm{M}$ be the set of elements with a "-" label, then determine $\in=\min \{x i j \mid(i, j) \in M\}$ and determine the improved transportation plan by

$$
x_{i j}= \begin{cases}x_{i j}+\in & \text { if }(i, j) \text { has a "+" label } \\ x_{i j}-\in & \text { if }(i, j) \in M \\ x_{i j} & \text { oterwise }\end{cases}
$$

Delete all labels and go to step 1 .

We illustrate the MODI method for finding an optimal solution using the above algorithm taken the above problem solved by NWC and VAM method

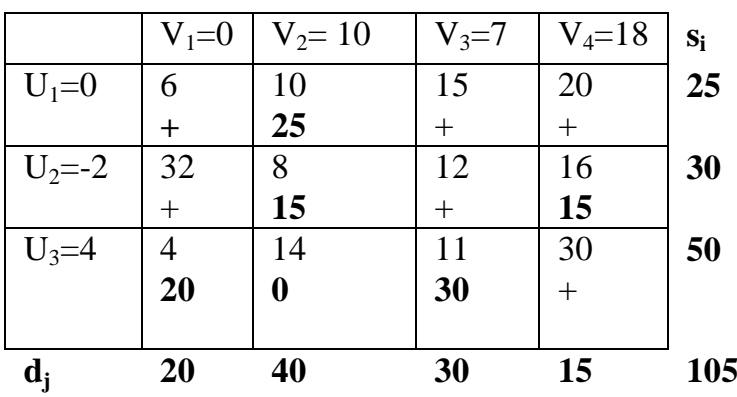

$u_{i}+v_{j}=c_{i j}$

$u_{1}+v_{2}=10 u_{1}=0 \Rightarrow v_{2}=10$

$u_{2}+v_{2}=8 v_{2}=10 \Rightarrow u_{2}=-2$

$u_{2}+v_{4}=16 u_{2}=-2 \Rightarrow v_{4}=8$

$u_{3}+v_{2}=14 v_{2}=10 \Rightarrow u_{3}=4$

$u_{3}+v_{1}=4 u_{3}=4 \Rightarrow v_{1}=0$

$u_{3}+v_{3}=11 u_{3}=4 \Rightarrow v_{3}=7$

$\mathrm{W} 1=(10 * 25)+(8 * 15)+(16 * 15)+(4 * 20)+(14 * 0)+(11 * 30)=10$

20

Evaluation of non-basic variables

Basis are $\mathrm{B}=\{(1,2)(2,2)(2,4)(3,1)(3,2)(3,3)\}$

The rest are non-basic variables .

$u_{i}+v_{j}=c_{i j} \quad(i, j) \notin B$

The solution by VAM is the optimal solution.

\subsection{The capacitated Transportation Problem}

In this subsection, we return to the original transportation structure with origins and destinations but without any transhipment nodes. Again, no two origins or destinations are connected, only connections from origins to destinations exist, but not all origin-destination pairs need to be connected. In addition to the unit transportation cost $c_{i j}$, capacities $\mathrm{k}_{\mathrm{ij}}$ are assigned to all arcs in the transportation network. The objective is to determine a cost-minimal transportation plan, where all supplies are shipped out of the origins, all demands are satisfied and the flows from origins to destinations do not exceed the given capacities. This problem can be stated in a mathematical term as:

Published By:

Blue Eyes Intelligence Engineering 
$P: \min z=\sum_{i=1}^{m} \sum_{j=1}^{n} c_{i j} x_{i j}$

s.t. $\sum_{j=1}^{n} x_{i j}=s_{i}, i=1, \ldots, m$

$$
\sum_{i=1}^{m} x_{i j}=d_{j}, j=1, \ldots, n
$$

$\left.\begin{array}{c}x_{i j}<k_{i j} \\ x_{i j} \geq 0\end{array}\right\}, i=1, \ldots, m, j=1, \ldots, n$

Introducing slack variables sij, $\mathrm{i}=1,2, \ldots . ., \mathrm{m}$ and $\mathrm{j}=1,2, \ldots \ldots ., \mathrm{n}$ for all constraints in (24), the capacity constraints can be written as

$x_{i j}+S_{i j}=k_{i j} \forall i, j$ or $x_{i j}=k_{i j}-S_{i j} \forall i, j$

summing up all equalities in (25) over $\mathrm{j}$, we obtain

$\sum_{j=1}^{n} x_{i j}=\sum_{j=1}^{n} k_{i j}-\sum_{j=1}^{n} s_{i j}, j=1,2, \ldots \ldots . m$

using (15),(16) can be written as

$\sum_{j=1}^{n} k_{i j}-\sum_{j=1}^{n} s_{i j}=s_{i}, \quad i=1,2, \ldots \ldots . m$

or, since all kij are given constant, as

$\sum_{j=1}^{n} s_{i j}=\sum_{j=1}^{n} k_{i j}-s_{i}, i=1,2, \ldots \ldots . m$

Now the capacitated transportation problem can be written in terms of $2 \mathrm{mn}$ variables xij and sij with the above objective function and constraints (26), (23), and (24)as well as the non-negativity constraints for all variables.

$P: \min z=\sum_{i=1}^{m} \sum_{j=1}^{n} c_{i j} x_{i j}$

$\sum_{j=1}^{n} s_{i j}=\sum_{j=1}^{n} k_{i j}-s_{i}, i=1,2, \ldots \ldots . m$

$\sum_{i=1}^{m} x_{i j}=d_{j, j}=1,2, \ldots n$

$\left.\begin{array}{l}x_{i j}+s_{i j}=k_{i j} \\ x_{i j}, s_{i j} \geq 0 .\end{array}\right\}$

The above problem $\mathrm{P}^{\prime}$ is now an ordinary transportation problem. If all variables xijand sij are in the positions indicated above, then the rows assume that constraints (14) are fulfilled, the first $\mathrm{n}$ columns guarantee that constraints (12) are fulfilled and the last $m$ columns guaranteed that constraints (19) are fulfilled. To ensure that all variables have values other than zero in the prescribed positions, we define costs given below,

$\tilde{c}_{i j}=\left\{\begin{array}{l}c_{i j}, \text { if the corresponding entry in T belongs to a variable } x_{i j} \\ 0, \text { if the corresponding entryin T belongsto a variable } s_{i j} \\ M, \text { otherwise. }\end{array}\right.$

\section{CONCLUSION}

At the beginning of chapter-I, we are given a brief account of the transportation problem. Most of the operations research papers are aware of the transportation problem. Since the transportation problem is a linear programming problem, the simplex method is applicable to solve the transportation problem. But the simplex method takes a lot of time to solve the transportation problem. It is found that when TP is put into the format of LP. The Transportation matrix is an unitary matrix whose determinants $|I|= \pm 1$ $(m+n-1)$. Where ' $m$ ' number of production centers (warehouses) and ' $n$ ' number of destinations. It has a basic feasible solution(BFS). And from the BFS the optimal solution is found out. There are several methods available for BFS, we briefly quote NWC rule, matrix minima method, Row/Column minima method, and penalty or Vogel's approximation method. We only give two algorithms, one is NWC rule and the other is Vogel's Approximation Method (VAM). Since TP is LPP we found out dual of TP and a dual variable. We used the MODI method to find the optimal solution. Numerical problems are quoted for the solution.

\section{REFERENCES}

1. Abbas Sayadi Bander, VahidMorovati,and HadiBasirzadeh, A super non-dominated point for multi-objective transportation problem, Applications and Applied Mathematics: An International Journal (AAM),10, 2015, 544 - 551.

2. Adlakha, V. and Kowalski, K.,An alternative solution algorithm for certain transportation problems,IJMEST,30, 1999, 719-728.

3. Ahuja, R.K., Algorithms for minimax transportation problem, Naval Research Logistics Quarterly, 33,1986, 725- 739.

4. Arsham, $\mathrm{H}$ and Khan AB., A Simplex-type algorithm for general transportation problems; An alternative to stepping-stone, Journal of Operational Research Society, 40, 1989, 581-590.

5. Arsham, H.,Post-optimality analysed of the transportation problem, Journal of theOperational Research Society,43, 1992, 121 $-139$.

6. Appa G.M., The Transportation problem and its variants, Oper. Res. Q. , 24,1973, 79-99.

7. Arora S.R. and Ahuja A., A paradox in a fixed charge transportation problem. Indian Journal pure appl. Math., 31, 2000,809-822.

8. Tkacenko. and A. Alhazov.,The multiobjective bottleneck transportation problem, Computers Science Journal of Moldova, Kishinev, 9, 2001, 321 - 335.

9. A. Tkacenko., The generalized algorithm for solving the fractional multi-objective transportation problem, ROMAI J., 2, 2006, 197 202.

10. Ali. I., Raghav, Y.S., and Bari, A., Integer goal programming approach for finding a compromise allocation of repairable components, International Journal of Engineering Science and Technology, 3, 2011a, 184-195.

11. Ali. I., Raghav, Y.S., and Bari, A., Compromise allocation in multivariate stratified surveys with stochastic quadratic cost function, Journal of Statistical computation and Simulation, 83, 2011b, 960-974.

12. Ammar.E. E. and Youness, E. A., Study on multi-objective transportationproblem with fuzzy numbers, Applied Math and Computation, 166,2005,241-253.

13. Bazaraa.M.S.,Jaruis, J.J., and Sherali, H.D., Linear programming and Network flows, John Wiley and Sons, New York, 1997.

14. Bhatia.H.L.,KantiSwaroop and M.C. Puri.,A procedure for time minimization transportation problem, 7th Annual Conference of ORSI at Kanpur, 1974.

Published By:

Blue Eyes Intelligence Engineering

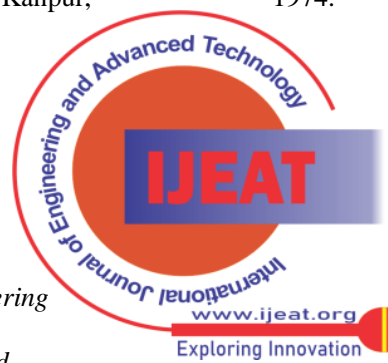


15. Bit. A. K. and Alam, S. S., An additive fuzzy programming model for multi-objective transportation problem, Fuzzy Sets and Systems, 57, 1993, 313-319.

16. Bit, AK, Biswal MP, Alam, SS., Fuzzy programming approach to multi-criteria decision making transportation problem, Fuzzy Sets and Systems, 50, 1992, 35-41.

17. Charnes. A. and Klingman, D., The More-for-less paradox d'EtudesRechercheOperationnelle, 13, 1971, 11-22.

18. Charnes. A., S. Duffuaa and Ryan, M., The More- for-Less Paradox in Linear Programming, European Journal of Operation Research, 31, 1987, 194-197.

19. Charnes, A., Cooper, W.W., The stepping stone method for explaining linear programming calculation in transportation problem, Mgmt. Sci., 1, 1954, 49 - 69.

20. Charnes, A., Cooper, W.W., and Henderson, A., An Introduction to Linear Programming, Wiley, New York, 1953.

21. Chandra. S and P.K. Saxena., Time Minimizing Transportation Problem with impurities, Asia- Pacific J. Op.Res.,4, 1987, 19-27.

22. Currin.D.C.,Transportation problem with inadmissible routes. Journal of the Operational Research Society,37, 1986, 387-396.

23. Dantzig, G.B., Linear Programming and Extensions, Princeton University Press, Princeton, N J , 1963.

24. Das.S.K.,Goswami.A and Alam.S.S.,Multi-objective transportation problem with interval cost, source and destination parameters, European Journal of Operational Research, 117, 1999, 100-112.

25. Garfinkel.R.S and Rao.M.R., The bottleneck transportation problem, Naval Research Logistics Quarterly, 18, 1971, 465 - 472.

26. Gaurav Sharma,S. H. Abbas, Vijay kumar Gupta., Solving Transportation Problem with the help of Integer Programming Problem, IOSR Journal of Engineering, 2 , 2012, 1274-1277.

27. Gupta, A., Khanna, S., and Puri, M.C.,Paradoxical situations in transportation problems, Cahiers du Centre d'EtudesRechercheOperationnelle, 34, 1992, 37-49.

28. Hitchcock, F.L., The distribution of a product from several sources to numerous localities. Journal of Mathematics \& Physics, 20, 1941, 224-230.

29. Ho. H.W. \& Wong, S.C. ,Two-dimensional continuum modelling approach to transportation problems, Journal of transportation Systems Engineering and Information Technology, 6, 2006,53-72.

30. Hadley. G.,Linear Programming, Addition-Wesley Publishing Company, Massachusetts, 1972.

31. Hammer.P.L., Time minimizing transportation problems, Naval Research Logistics Quarterly, 16, 1969, 345 - 357.

32. Hussien, M. L., Complete solutions of multiple objective transportation problemwith possibilistic coefficients, Fuzzy Sets \& Systems, 93, 1998, 293-299.

33. Ignizio, J.P.,Goal Programming and Extensions, Lexington Books, Massachusetts, 1976.

34. Ilija Nikolic'., Total time minimizing transportation problem, Yugoslav Journal of Operations Research, 17, 2007, 125-133.

35. Isermann.H., Bielefeld.,Solving the transportation problem with mixed constraints, Zeitschrift fur Operations Research, 26, 1982, 251-257.

36. Isermann.H.,The enumeration of all efficient solution for a linear multiple-objective transportation problem, Naval Res Logistics Quarterly,26,1979, 123-139.

37. Issermann.H.,Linear bottleneck transportation problem, Asia Pacific Journal of Operational Research, 1, 1984, 38 - 52

38. Jain.M and Saksena.P.K.,Time minimizing transportation problem with fractional bottleneck objective function, Yugoslav J of Operations Research, 22, 2012, 115-129.

39. Joshi, V. D. and Gupta, N.,On a paradox in linear plus fractional transportation problem, Mathematika,26, 2010, 167-178.

40. Kasana, H.S., and Kumar, K.D., Introductory Operations Research Theory and Applications, Springer International Edition, New Delhi, 2005.

41. Kavitha. $\mathrm{K}$ and Anuradha.D., Heuristic algorithm for finding sensitivity analysis of a more for less solution to transportation problems, Global Journal of Pure and Applied Mathematics, 11, 2015, 479-485.

42. Khanna.S, Bakhshi.H.C and Arora.S.R.,Time minimizing CentredeRechercheOperationelle, 25, 1983, 65-74.

43. Kirca and Statir., A heuristic for obtaining an initial solution for the transportation problem, Journal of operational Research Society, 41,1990, 865-867.

44. Klibi.W, F. Lasalle, A. Martel and Ichoua.S., The stochastic multiperiod location transportation problem, Transportation Science,44, 2010, 221-237. in distribution models, Cahiersdu Centre transportation problem with restricted flow, Cahiers du

45. Klein, M., A primal method for minimal cost flows with applications to the assignment and transportation problems, Management Science,14,1967, 205-220.

46. Korukoglu.S and Balli.S.,An Improved Vogel's Approximation Method for the Transportation Problem, Association for Scientific Research, Mathematical and Computational Application,16, 2011, 370-381.

47. Koopmans, T.C., (1947), Optimum utilization of the transportation system, in: The Econometric Society Meeting (Washington, D.C., September 6-18, D.H. Leavens, ed.) [proceedings of the International Statistical Conference- Volume V, 1948,136-146] [reprinted in: Econometrica 17, 1949, 136-146] [reprinted in: Scientific papers of Tjalling C. Koopmans, Springer, Berlin, 1970,184-193]

48. Koopmans, T.C., andReiter.S.,A model of transportation, in: Activity Analysis of Production and Allocation, Proceedings of a Conf.(Koopmans, ed., ), Wiley, New York, 1951, 222-259.

49. Krzysztof Goczyla, JanuszCielatkowski.,Case study Optimal routing in a transportation network, European Journal of Operational Res, 87,1995, 214-222.

50. Kwak, N.K. andSchniederjans, M.J.,A goal programming model for improved transportation problem solutions, Omega, 12, 1979, $367-$ 370.

51. Kwak N.K. andSchniederjans, M.J., Goal programming solutions to transportation problems with variable supply and demand requirements, Socio-Economic Planning Science, 19,1985, 95-100.

52. Lau, H. C. W., Chan, T. M., Tsui, W. T., Chan, F. T. S., Ho, G. T. S and Choy, K. L., A fuzzy guided multi- objective evolutionary algorithm model for solvingtransportation problem, Expert System with Applications: An InternationalJournal, 36, 2009, 8255-8268.

53. Lee, S.M., Goal Programming for Decision Analysis, Auerbach, Philadelphia, 1972.

54. S.M. Lee and L.J., Moore, Optimizing transportation problems with multiple objectives, AIEE Transactions, 5, 1973, 333-338.

55. Leberling, H., On finding compromise solutions for multi-criteria problemsusing the fuzzy min-operator, Fuzzy Sets and Systems, 6, 1981, 105-118

56. Li, L. and Lai, K. K., A fuzzy approach to the multi-objective transportation problem, Computers and Operational Research, 28 2000, 43-57.

57. Lohgaonkar, M. H. and Bajaj V. H., Fuzzy approach to solve multiobjectivecapacitated transportation problem, Int J. of BioinformaticsRes,2, 2010, 10-14.

58. Madhuri.D.,Linear fractional time minimizing transportation problem with impurities, Information Sciences Letters, 1, 2012, 7-19.

59. Mistuo GE, Yinzhen.Land Kenichi ID., Solving Multi-Objective Transportation Problem by Spanning Tree- Based Genetic Algorithm, IEICE Trans. Fundamentals, E82-A, 1999, 2802-2810.

60. MollahMesbahuddin Ahmed, Abu Sadat Muhammad Tanvir, Shirin Sultana, Sultan Mahmud and Md. Sharif Uddin., An Effective Modification to Solve Transportation Problems: A Cost minimization Approach, Annals of Pure and Applied Mathematics,6, 2014, 199-206.

61. Okunbor, D., Management decision-making for transportation problems through goal programming, $\mathrm{J}$ of Academy of Business and Econ.,4,2004, 109-117.

62. Osuji George A., Opara Jude, Nwobi Anderson C., Onyeze Vitus, Iheagwara Andrew I., Paradox Algorithm in Application of a Linear Transportation Problem, American Journal of Applied Mathematics and Statistics,2, 2014, 10-15.

63. Osuji, George A, Okoli Cecilia N, Opara, Jude, Solution of multiobjective transportation problem via fuzzy programming algorithm, Science Journal of Applied Mathematics and Statistics, 2, 2014, 7177.

64. Pandian.P and Natarajan.G., A new method for finding an optimal solution for transportation problems, International Journalof Math. Sci. and Engg. Appls.,4,2010, 59 - 65.

65. Pandian, P and Anuradha.D., Path Method for Finding a More-ForLess Optimal Solution to Transportation Problems, International Conference on Mathematical Computer Engineering, 1, 2013, 331337.

66. Pandian, P., and Natarajan, G., Fourier method for solving transportation problems with mixed constraints, Int. J of Contemp. Math Sciences, 5, 2010a, 1385-1395.

Published By:

Blue Eyes Intelligence Engineering and Sciences Publication

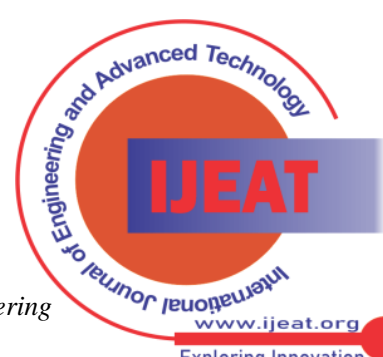

Exploring Innovation 
67. Pandian, P., and Natarajan, G., A new method for finding an optimal more-for-less solution of transportation problems with mixed constraints, Int. J. Contemp. Math. Sciences, 5, 2010b, 931-942.

68. Pandian.P and Natarajan.G., A new method for solving bottleneck cost transportation problems, International Mathematical Forum, 6 , 2011, 451 - 460.

69. Pandian.P and D.Anuradha., A new approach for solving biobjective transportation problems,Australian Journal of Basic and Applied Sciences, 5, 2011, 67-74.

70. Pavel Kolman, Time minimizing transportation problems with partial limitations of transported amount for transport participants, AIP Conf. Proc, 1648, 2015

71. PeerayuthCharnsethikul and SaereeSvetasreni.,The Constrained Bottleneck Transportation Problem, Journal of Mathematics and Statistics,3, 2007, 24-27.

72. Ping Ji, Chu KF., A dual - Matrix approach to the transportation problem, Asia -Pacific Journal of Operation Research, 19, 2002, 35 45.

73. Putcha. C.S., and Shekaramiz.A., Development of a new method for arriving at initial basic feasible solution for optimization problems in Engineering, 23rd European Conference on Operational Research, Bonn, 2009.

74. RabindraNathMondal, Farhana Rashid, Poly Rani Shaha, Raju Roy. An Innovative Method for Unraveling Transportation Problems with Mixed Constraints, American Journal of Mathematics and Statistics , 5, 2015, 190- 195.

75. RadindraNathMondal and Md. Rezwan Hossain.,Solving Transportation Problem with Mixed Constraints, Proceedings of International Conference on Industrial Engineering and Operations Management, 2012, 1927- 1932

76. Ravi Varadarajan, An optimal algorithm for $2 \times \mathrm{n}$ bottleneck transportation problems, Operations Research Letters,10, 1991, 525529.

77. Rayan, M., More-for-less paradox in distribution model, Extremal methods and systems analysis, Springer, New York, 1978.

78. Rekha.S.,B.Srividhya Minimization: Max Min Penalty A Mathematics,10, 2014, 06-08.

79. RekhaVivek Joshi, Optimization Techniques for Transportation Problems of Three variables, IOSR Journal of Mathematics, 9, 2013,46-50.

80. Rita Malhotra, On bi-criteria transportation problem, Combinatorial Optimization: Some Aspects ,Narosa Publishing House, New Delhi, India, 2007.

81. Ringuest.J.L.,and D.B. Rinks, Interactive solutions for the linear multi-objective transportation problem, European Journal of Operational Research, 32 , 1987, 96-106.

82. Robb, D. J.,The more- for-less paradox in distribution models: An intuitive explanation, IIE Transactions, 22, 1990, 377-378.

83. Sarbjit Singh, Note on Transportation Problem with New Method for Resolution of Degeneracy, Universal J. of Industrial and Business Management,3, 2015, 26-36.

84. Sayed A. Zaki, Abd Allah A. Mousa, Hamdy M. Geneedi, Adel Y Elmekawy,Efficient multi-objective genetic algorithm for solving transportation, assignment, and transshipment Problems, Applied Mathematics, 3, 2012, 92-99.

85. Schrijver, A., On the history of the transportation and maximum flow problems, Mathematical Programming, 91,2002, 437-445.

86. Seshan, C.R., and Tikekar, V.G., On Sharma-Swarup algorithm for time minimizing transportation problems, Proc. Indian Acad. Sci. 89, 1980, 101-102.

87. Sharma, Gaurav; Abbas, S. H.; Gupta, Vijay, Optimum Solution of Transportation Problem with the help of phase-II method of Simplex Method, Indian journal of applied life science, 6, 2011, 49-54

88. Sharma, Gaurav; Abbas, S. H.; Gupta, Vijay, Dual Simplex Algorithm for Proctor \& Gamble to Solve Transportation Problem, Journal of Ultra Scientist of Physical Sciences, 23, 2011.

89. Sharma..R.R.K, andSharma.K.D., A new dual based procedure for the transportation problem, European Journal of Operational Res., $122,2000,611-624$

90. Sharif Uddin.M.,Transportation Time Minimization: An Algorithmic Approach, Journal of Physical Sciences, 16, 2012, 59-64

91. Sharma, J.K. and K. Swarup,Time minimizing transportation problem, Proceeding of Indian Academy of Sciences (Math. Sci.), 86, 1977, 513-518.

92. Sharma, J.K., and K.Swarup, Transportation fractional programming with respect to time, Ticerca Operativa,7, 1978, 49-58.

93. Sonia and M.C.Puri, Two level hierarchical time minimizing transportation problem, TOP,12, 2004, 301-330.
94. Storoy, S, The transportation paradox revisited, N-5020 Bergen, Norway, 2007.

95. Sudhakar VJ, Arunnsankar N, Karpagam T., A new approach for find an Optimal Solution for Trasportation Problems, European Journal of Scientific Research,68, 2012, 254-257.

96. Sultan, A., Heuristic for Finding an Initial B. F. S. in Transportation Problems, Opsearch, 25, 1988, 197-199.

97. Sultan, A. and Goyal, S.K., Resolution of Degeneracy in Transportation Problems, Journal Operational Research Society, 39 1988,411-413.

98. Surapati, P. and Roy, T. K., Multi-objective transportation mode with fuzzyparameters: Priority based fuzzy goal programming approach, Journal ofTransportation Systems Engg.and Information Technology, 8, 2008, 40-48

99. Sun, M., The transportation problem with exclusionary side constraints and branch-and-bound algorithms, European Journal of Operational Res, 140,2002,629-647.

100. SzwarcW.,The transportation paradox, Naval Res. Logistics. Q., 18 1971, 185-202.

101. Szwarc.W., Some remarks on the transportation problem, Naval Research Logistics Quarterly, 18, 1971, 473 - 485.

102. Taghrid Imam Gaber Elsharawy Mohamed Gomah Iman Samy , Solving Transportation Problem Using Object- Oriented Model, International Journal of Computer Science and Network Security, 9, 2009, 353-361.

103. Veena Adlakha, Krzysztof Kowalski,Alternate Solutions Analysis For Transportation problems, Journal of Business \& Economics Research,7, 2009.

104. Veena Adlakha and K. Kowalski., A Quick Sufficient Solution to the More for Less Paradoxin Transportation Problem, Omega, 26, 1998, 541-547.

105. Veena Adlakha and K. Kowalski., A Heuristic Method for More-forLess in Distribution Related Problems, International Journal of Mathematical Education in Science and Technology,32, 2001, 6171.

106. Veena Adlakha, K. Kowalski and B. Lev, Solving Transportation Problem with Mixed Constraints, International Journal of Management Science and Engineering management, 1, 2006, 47-52.

107. Veena Adlakha, K. Kowalski, R. R.Vemuganti, and B. Lev, Morefor-less algorithm for fixed charge transportation problems, Omega, 35, 2007, 116-127.

108. Verma, R., Biswal, M. P. and Verma, A. B., Fuzzy programming technique tosolve multi-objective transportation problems with some non-linear membership functions, Fuzzy Sets and Systems, 91, 1997, 37-43.

109. Verma, R., Biswal, M. P., Biswas, A., Fuzzy programming technique to solve multi-objective Transportation problem with some nonlinear membership functions, Fuzzy sets and systems,91, 1997, 37 43.

110. Vishwas Deep Joshi and Nilama Gupta, Identifying more-for-less paradox in the linear fractional transportation problem using objective matrix, Mathematika, 28, 2012, 173-180.

111. Waiel F. and Abd El-Wahed,A multi-objective transportation problem under fuzziness, Fuzzy Sets and Systems, 117, 2001, 27-33.

112. Wahed, W. F. and Sinna, M. A., A hybrid fuzzy-goal programming approach tomultiple objective decision making problems, Fuzzy Sets and Sy, 119, 2001, 71-85.

113. WuttinanNunkaew and BusabaPhruksaphanrat,Amulti-objective programming for transportation problem with the consideration of both depot to customer and customer to customer relationships, International Multi Conference of Engineers and Computer Scientists, 2009.

114. Zangiabadi, M. and Maleki, H. R., Fuzzy goal programming for multi-objectivetransportation problems, Applied Math and Comp, 24,2007, 449-460.

115. Żółkiewski.S., Modelling of dynamical systems in transportation using the modyfit application, Journal of Achievements in Materials and Manufacturing Engineering, 28, 2008, 71-74.

116. Zeleny.M., Multiple criteria decision making; Mc Graw-Hill Book Company, 1982.

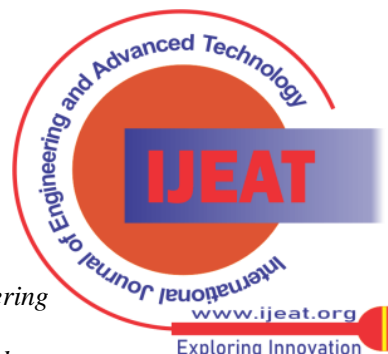




\section{AUTHORS PROFILE}

Mrs. Bhabani Mallia, M.Phil. in Statistics from Utkal University, Bhubaneswar, Odisha. And continuing Ph.D at SOA deemed to be University, Bhubaneswar. She is working under the joint guidance of Prof. Manjula Das, Prof. C. Das in the field of transportation problem and goal 3 programming. She has completed some paper on the topic and carrying on her research for Ph.D. degree under SOA deemed to be University.

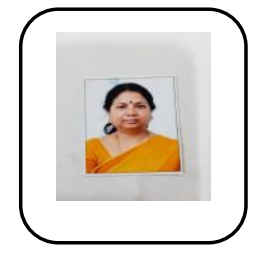

Dr. Manjula Das, is presently working as a Professor in the Centre for Applied Mathematics \& Computing at SOA deemed to be University, Bhubaneswar. She has a teaching experience of 25 years in Mathematics \& Statistics and 15 years of research experience in the area of Statistical Analysis of data. Presently working in the field of Transportation Engineering in Operations Research. Under her guidance two students are continuing their research. She has published six number of paper in different national / international journals and also presented some papers in national conferences.

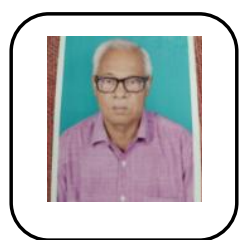

Dr. C. Das, a retired Professor of Mathematics, from NIIT, Rourkela, Odisha a well-known figure in Operations Research, particularly in the area of Mathematical Programming and its applications to Transportation, assignment, networking system, petrinet modelling, graph theory, fuzzy set etc. He has a lots of contributions in polynomial (interior point) algorithms for linear and non- linear mathematical programming problems. he has more than hundreds published papers in national and International journals of repute. he is also in editorial board of national and international journals and reviewer of some international journals. After retirements, he is also active in research in operation research and some allied topics.

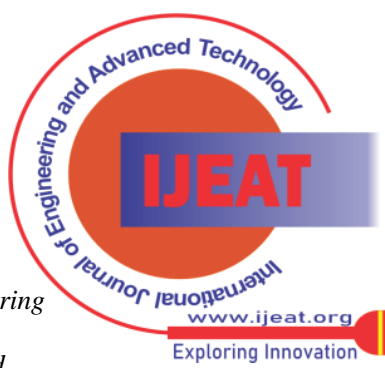

